\title{
Implementação da Lei 10.639/2003: mapeando embates e percalços
}

\section{Implementation of the Law 10.639/2003: mapping clashes and mishaps}

\author{
Florentina da Silva Souza ${ }^{1}$ \\ Leticia Maria da Souza Pereira ${ }^{2}$
}

\begin{abstract}
RESUMO
Este artigo tem por objetivo analisar os embates e sucessos encontrados por estudantes e docentes de escolas públicas no desenvolvimento de práticas pedagógicas voltadas para a implementação da Lei 10.639/2003. A reflexão crítica visa contribuir para discussões sobre Educação das Relações ÉtnicoRaciais e, para tanto, recorremos a entrevistas e observações feitas em escolas de quatro Estados da região Nordeste durante a pesquisa nacional "Práticas Pedagógicas de Trabalho com Relações Étnico-Raciais na Escola na Perspectiva da Lei 10.639/2003". São analisadas entrevistas realizadas com diretoras, coordenações pedagógicas e professoras/es, como também grupos de discussão formados por estudantes de seis diferentes escolas da região, sobre temas como: a constituição das identidades étnico-raciais, acesso a material didático e informativo sobre cultura brasileira e afro-brasileira. Nas discussões e entrevistas, constatamos que, não obstante algumas experiências exitosas, a maioria do corpo docente, gestores/as e funcionários/as das escolas investigadas carece ainda de melhorar as informações e conhecimentos sobre a Lei 10.639/2003, sobre as Diretrizes Curriculares Nacionais para a Educação das Relações Étnico-Raciais e para o Ensino de História e Cultura Afro-Brasileira e Africana, além de outros documentos de orientação para a Educação das Relações Étnico-Raciais, com vistas a implementar práticas pedagógicas de feição intercultural que contribuam para a constituição de
\end{abstract}

${ }^{1}$ Doutora em Estudos Literários pela Universidade Federal de Minas Gerais, bolsista CNPq 2, professora associada da Universidade Federal da Bahia (Instituto de Letras da UFBA - ILUFBA e Centro de Estudos Afro-Asiáticos - CEAO), Brasil. E-mail: florenss@ufba.br

${ }^{2}$ Doutoranda em Literatura e Cultura pela Universidade Federal da Bahia, bolsista CAPES, Brasil. E-mail: laeticias@hotmail.com 
espaços educacionais nos quais a diferença e a diversidade sejam respeitadas e valorizadas.

Palavras-chave: Lei 10.639/2003; Nordeste; educação; práticas pedagógicas.

\begin{abstract}
This article's intent is to analyze the difficulties and successes of public school students and faculty in the development of pedagogical practices supporting the implementation of Law 10.639/2003. This critical reflection looks to contribute to discussions about Ethnic-Racial Relations Education and in order to do that, we utilize interviews and observations realized at schools in four northeastern States during the national research "Pedagogical practices with ethnic-racial relations in the school from the perspective of Law 10.639/2003". We analyze interviews conducted with school directors, pedagogical coordinators, and teachers, as well as with discussion groups comprised of students from six different schools of the region, about themes such as: the constitution of ethnic-racial identities, access to educational material, and information about Brazilian and Afro-Brazilian culture. The discussions and interviews showed that, despite some positive experiences, the majority of the faculty, directors, and employees of the schools under investigation were in need of information and knowledge about the Law 10.639/2003, about the National Curricular Guidelines for Ethnic-Racial Relation Education and for the Teaching of Afro-Brazilian History and Culture, as well as about other helpful documents concerning ethnic-racial relations education, thus hindering the implementation of intercultural pedagogical practices that contribute to the constitution of educational spaces in which difference and diversity are respected and valued.
\end{abstract}

Keywords: Law 10.639/2003; Brazilian Northeast; education; pedagogical practices.

\title{
Introdução
}

A pesquisa "Práticas Pedagógicas de Trabalho com Relações Étnico-Raciais na Escola na Perspectiva da Lei 10.639/2003", realizada, em 2009, pelo Programa de Ações Afirmativas da UFMG, em parceria com a Secretaria de Educação Continuada, Alfabetização, Diversidade e Inclusão - SECADI/ $\mathrm{MEC}$ - e a representação da UNESCO no Brasil, buscou mapear nacionalmente e analisar os modos através dos quais a implementação da Lei 10.636/2003 tem se configurado na rede pública de ensino do país. Este artigo abordará, especifi- 
camente, como a Região Nordeste I, compreendendo os Estados do Maranhão (São Luís), Bahia (Salvador e Jequié), Sergipe (Aracaju) e Ceará (Horizonte).

Os Estados estão situados na chamada região Nordeste, que corresponde a $18,26 \%$ do território nacional, ou seja, $1.561 .177,8 \mathrm{~km}^{2}$, uma área pequena em se considerando a extensão do país, mas que historicamente exerceu um papel primordial no processo de implementação da empresa colonial portuguesa e da expansão econômica e cultural da então colônia, haja vista que, durante o século XVII, foi o grande centro econômico e cultural do país. Nos séculos seguintes, a região foi gradativamente perdendo o lugar de destaque na vida política do Brasil e em alguns momentos foi definido como "espaço do atraso". O estudioso Albuquerque Jr. (2006, p. 24), no seu livro A invenção do Nordeste e outras artes, define assim a região:

[...] é pensá-la como um grupo de enunciados e imagens que se repetem, com certa regularidade, em diferentes discursos, em diferentes épocas, com diferentes estilos e não pensá-la em uma homogeneidade, uma identidade presente na natureza.

Atualmente, a região apresenta os maiores índices de pobreza e desigualdade social, predominando baixo índice de escolaridade da população e precárias condições de saúde, educação e habitação.

\section{Pesquisa Nordeste I}

Para a pesquisa, foi disponibilizada pela Coordenação Nacional uma lista contendo nomes de trinta escolas da rede pública do ensino dos Estados correspondentes à região Nordeste I. As escolas foram indicadas pelas Secretarias Estaduais de Educação, Secretarias Municipais de Educação, Núcleos de Estudos Afro-Brasileiros (NEABs) e Centro de Estudos das Relações de Trabalho e Desigualdades (CEERT) como aquelas que desenvolviam práticas de implementação da Lei 10.639/2003; dentre elas, foram escolhidas apenas seis para o trabalho em campo. A metodologia utilizada pelas pesquisadoras da Regional Nordeste $\mathrm{I}^{3}$ para formação do corpus consistiu em aplicação de

\footnotetext{
${ }^{3}$ Equipe composta por: coordenadora Profa. Dra. Florentina Souza; pesquisadoras Letícia Maria Pereira e Ires Brito, e as estagiárias Daniela Sacramento, Vanessa França e Rebeca Brito.
} 
questionário-sondagem com o/a gestor/a da escola através de contato telefônico. No processo de seleção, buscou-se identificar o desenvolvimento de ações efetivas para implementação da Lei 10.639/2003 E, ainda, contemplar instituições de zonas urbanas e rurais e de diferentes níveis educacionais. Assim, chegou-se ao seguinte corpus na Bahia: duas escolas em Salvador, sendo uma que atende aos níveis infantil e fundamental (indicadas pelo CEERT e SEED) e uma de nível fundamental; e outra de nível fundamental I, II e EJA, no interior do Estado, a cidade de Jequié (indicada pelo NEAB). Na capital baiana, a Escola Municipal 1 possui 10 salas de aula, uma biblioteca, 3 salas administrativas, 3 banheiros e 1 pátio; já a Escola Estadual 2 possui apenas 6 salas de aula e uma sala administrativa, copa, brinquedoteca, 3 banheiros e 1 pátio. Ambas localizam-se na região metropolitana de Salvador, que dispõe de um pequeno comércio e disponibilidade restrita de serviços, com grande atuação do tráfico de drogas e índices expressivos de violência. Situada também num bairro popular, a Escola Municipal 3, de médio porte, no município de Jequié/BA, funciona em um antigo ginásio de esportes da cidade e não tem biblioteca.

No Estado de Sergipe (indicada pelo CEERT), uma escola estadual de nível médio (Escola Estadual 4), conhecida por sua "excelência", fica localizada em um bairro residencial no centro da capital sergipana. Possui 22 salas, 8 laboratórios, 5 banheiros, 2 vestiários, 1 refeitório, uma quadra, uma sala do grêmio estudantil, entre outros.

A Escola Estadual 5 situa-se em um bairro de muitas manifestações culturais de São Luís/MA. O colégio apresenta um amplo espaço: aloca 37 salas, 7 laboratórios, duas quadras, 1 auditório, uma sala dos/as professores/as, 13 banheiros com chuveiro e uma biblioteca.

E no Estado do Ceará (indicação da SMED), uma escola que atende à educação infantil e ao ensino fundamental (Escola Municipal 6), no município de Horizonte, situa-se na zona rural, isolada do centro da cidade, de difícil acesso. A escola possui 5 salas de aula, uma cantina, 1 almoxarifado, 1 depósito, uma secretaria, 3 banheiros e 1 corredor onde funciona uma "biblioteca".

Após a seleção, as pesquisadoras passaram de 6 a 10 dias nas escolas para efetivar ações de observação direta das práticas pedagógicas para implementação da Lei 10.639/2003, análises de documentos pedagógicos, entrevistas com gestores/as, professores/as, estudantes e funcionários/as. Assim, o grupo teve a oportunidade de conhecer diversos pontos de vista sobre as estratégias utilizadas por essas escolas para o cumprimento da referida Lei. 


\section{As práticas pedagógicas - NE I}

As seis escolas que compuseram nosso corpus de análise de fato desenvolvem atividades voltadas para implementação da Lei 10.639/2003, porém evidenciam modos diferenciados de compreensão do que prevê a legislação: algumas criaram disciplinas de História e Cultura Afro-Brasileira e outras desenvolvem projetos destinados à implementação. A seguir, analisaremos algumas das práticas observadas nas escolas do corpus da pesquisa.

Duas das escolas, a de Jequié/BA e a de Horizonte/CE, criaram no currículo uma disciplina intitulada "História e Cultura Afro-Brasileira", tornada obrigatória pelas respectivas secretarias municipais, e procuraram disponibilizar cursos de formação em serviço específica para os/as professores/as que iriam ministrar a disciplina.

Entendemos a tentativa das secretarias municipais de atender ao que exige a Lei, entretanto, a criação de disciplinas isoladas e específicas não propicia o alcance dos objetivos da legislação nem evidencia os fundamentos teórico-metodológicos da disciplina, o que prejudica bastante a implementação da citada Lei, de modo que se torna difícil afirmar se as práticas refletem ou ecoam propósitos políticos de reparação quanto ao silenciamento da participação ativa dos negros e negras e suas culturas na formação da história, cultura e riqueza do país, ou ainda quanto ao seu papel na afirmação de identidades culturais colocadas à margem do discurso nacional.

Os/As professores/as que ministram a disciplina lamentam que a carga horária destinada à formação para a docência da disciplina não seja suficiente para discussão do conteúdo programático, gerando dificuldades para o estabelecimento de um diálogo interdisciplinar, tanto no tocante aos conteúdos quanto ao envolvimento dos demais atores da escola nas discussões e atividades propostas pela disciplina. Por outro lado, vale relatar que na EM3 e na EM6 as disciplinas são ministradas apenas para o ensino fundamental de nível II. Situação indicativa da precariedade do processo de cumprimento da obrigação legal, não somente porque os conteúdos e práticas ficam restritos a uma disciplina específica, mas também porque a disciplina só faz parte da grade curricular de parte do fundamental.

Enfim, vários questionamentos críticos podem ser feitos quanto à metodologia utilizada, quanto ao caráter prescritivo, restritivos de alguns conceitos e em um dos casos constatamos a reiteração de preconceitos e estereótipos sobre a cultura afro-brasileira, como ilustra a informação colocada no quadro de giz por um professor da disciplina História e Cultura Afro-Brasileira: "Quanto me- 
nor a presença de tambores na música, mais qualidade musical. Por isso que a música negra americana é melhor que a musicalidade negra do Brasil, que tem muito uso da percussão".

Em Aracaju/SE e São Luís/MA, as escolas possuem, respectivamente, os projetos "Um quê de negritude" e "Mãe África", sob a responsabilidade de professores/as específicos/as que, individualmente, elaboram e coordenam algumas atividades voltadas para a temática da História e Cultura do Negro no Brasil, sempre com o apoio do gestor.

Nas ações individuais, quase que totalmente desvinculadas das atividades curriculares, não se observa a participação generalizada da comunidade escolar, os projetos não se constituem elo de integração da comunidade e o citado apoio do gestor, nos casos em foco, significou disponibilidade de espaço físico e de algum recurso financeiro para compra de material, sem qualquer envolvimento pessoal do mesmo na articulação com outros/as professores/as ou alunos/as ou mesmo nas ações desenvolvidas. Na EE5, o projeto "Mãe África", embora conste no Projeto Político-Pedagógico (PPP), está totalmente esvaziado de seus objetivos pedagógicos, reduzindo-se, de acordo com as palavras dos/as professores/as, às aulas e apresentações de dança afro, sem qualquer debate, discussão ou reflexão sobre os possíveis significados da dança nas tradições de matrizes africanas. O projeto de dança, realizado pela EE4, foi inserido na grade de atividades curriculares somente no ano letivo de 2009 e não conseguiu estabelecer interação interdisciplinar.

Assim, os projetos das escolas em análise terminam por não atuar como molas propulsoras de alterações, no que se refere ao trato com a diferença, nem obtêm êxito na implantação de uma educação antirracista, que fortaleça a autoestima dos estudantes negros e que possa levar todos os estudantes à compreensão da diversidade cultural do Brasil.

Vale destacar que consideramos a dança e a música elementos importantes na construção identitária afrodescendente, mas que precisam ser articulados a outros componentes deste processo de construção, como consta das Diretrizes Curriculares Nacionais de Educação para Relações Étnico-Raciais e em estudos teóricos de variados autores, os quais apontam a dança, a música e o corpo como instrumentos utilizados pelos africanos em todo o Atlântico Negro para resistir à objetivação. Stuart Hall (2003, p. 245-348) lembra que a música, o estilo, a oralidade e até mesmo o corpo funcionam como capital teórico/simbólico para constituição de histórias e memórias. A nossa apreensão quanto à forma como estão sendo desenvolvidos os projetos citados deve-se ao fato de, nos momentos em que observamos, a música e a dança de origem africanas terem sido apropriadas e, ao que parece, desvestidas de sua carga de história e resistência que marcam a memória dos afrodescendentes nos espaços da diáspora. Para as 
tradições afrodiaspóricas, a música e a dança estão interligadas às atividades cotidianas e sagradas e, portanto, constituem espaços privilegiados para manutenção das tradições que foram desprestigiadas pelo discurso hegemônico que se desejava universal.

Somente nas duas escolas de Salvador/BA pudemos observar práticas pedagógicas que consideramos interessantes e mais integradas aos preceitos da Lei 10.639/2003. O diferencial dessas escolas é a inclusão de temáticas relacionadas à Educação das Relações Étnico-Raciais em todas as disciplinas e/ou nos projetos desenvolvidos, com a participação do coletivo escolar, comunidade e atuação efetiva dos gestores e coordenadores. Esta integração permite que as temáticas estejam presentes em várias atividades escolares como estruturantes dos trabalhos desenvolvidos pela comunidade escolar.

Elencamos a seguir algumas práticas consideradas significativas que foram desenvolvidas em algumas escolas que visitamos e que, "aperfeiçoadas", poderiam compor um banco de sugestões de atividades para outras escolas e professores/as:

- Produção de livro infanto-juvenil, de autoria de uma professora, que apresenta uma princesa negra que valoriza a cultura de seus antepassados africanos;

- Confecção de bonecas a partir de personagens negras de livros infantis;

- Elaboração de grupos de trabalhos voltados para hip-hop, capoeira, confecção de instrumentos musicais e grafitagem;

- Organização de desfiles na comunidade em comemoração ao dia 20 de Novembro (Dia Nacional da Consciência Negra);

- Convite a membros de blocos afros, comunidades de terreiros, capoeiristas e aos pais e mães dos estudantes para fazerem palestras ou darem oficinas na Escola relacionadas à valorização das culturas africana e afro-brasileira;

- Elaboração de projetos de pesquisas a respeito de histórias e contadores de história sobre a África e proposição de uma análise paralela com as Histórias dos Quilombos;

- Proposição de um projeto de rádio com programação especial sobre a temática racial;

- Projeto "Folhas Sagradas" como atividade de pesquisa, no qual os/as alunos/as catalogam nas comunidades de terreiro as plantas sagradas e divulgam na escola seus benefícios, buscando a preservação da natureza e o respeito às religiões de matriz africana;

- Programação de gincana sobre assuntos relativos à história e à cultura afro-brasileira; 
- Apresentação de coreografias inspiradas nos mitos dos Orixás;

- Exposição sobre os países africanos e suas culturas;

- Pesquisas sobre literatura e arte africanas;

- Palestra sobre as influências de línguas africanas no vocabulário brasileiro;

- Atividades de produção de cremes e xampus para cabelos crespos, sob a orientação da professora de química;

- Oficinas de teatro realizadas por várias escolas.

As práticas aqui citadas por vezes não foram desenvolvidas com metodologia que considerássemos pertinente e, muito menos, com base em conteúdos mais atualizados sobre a história e cultura africanas ou afrodescendentes; entretanto, revelam o desejo de atores das escolas de participarem do processo de implementação da Lei. Muitas das dificuldades de atualização estão relacionadas às gritantes desigualdades regionais, precariedade das escolas e dos processos de formação e atualização dos/as professores/as e certo desinteresse de vários setores do governo nas suas várias instâncias pelo fortalecimento do ensino público.

\section{Grupos de discussão}

Os grupos de discussão tinham por objetivo perceber de que modo o trabalho com a temática repercutia nos diálogos e debates entre os discentes. Foram realizados com dez estudantes de séries, gêneros e pertencimentos étnico-raciais diferentes, inicialmente com vistas a identificar as compreensões que os estudantes tinham sobre a África, assim como discutir as representações de afrodescendentes existentes na escola, para então analisar a inserção dos conteúdos no cotidiano das escolas e também a percepção que os estudantes tinham sobre identidade e diferença. No início tímidos, os estudantes terminaram por demonstrar que, na maioria dos casos, poucos possuíam uma visão de África que contrariasse os estereótipos mais frequentes na mídia. A notar em:

Eu queria conhecer a África por causa dos animais, que é muito rica em animais, a pobreza de lá é mais... as crianças de lá é mais pobre do que aqui, porque lá elas não têm várias coisas que a gente tem aqui (Estudante do $8^{\circ}$ ano). 
Podemos dizer que $50 \%$ dos alunos que participaram do grupo de discussão apresentam um nível de reflexão e análise crítica sobre a diversidade étnico-racial brasileira e os principais problemas dela decorrentes, a saber: a discriminação racial, o desconhecimento sobre as comunidades afro-brasileiras, demonização das religiões de matrizes africanas, a reprodução de estereótipos negativos, entre outros. A outra parte demonstrou conhecimentos estereotipados e equivocados sobre a África e bastante limitados sobre a cultura afro-brasileira. Também neste momento algumas situações de discriminação de base étnico-racial no ambiente escolar foram narradas pelos estudantes.

\section{Identidade em questão}

Nas seis escolas, constatamos que a maioria dos entrevistados tem dificuldade de assumir sua pertença étnico-racial. Esta situação, é bem verdade, não se restringe apenas às citadas pessoas, pelo contrário, no país da suposta democracia racial há uma recorrente dificuldade de não brancos assumirem-se afrodescendentes ou indiodescendentes. No trabalho em campo, mais de um gestor, ao definir o seu lugar étnico-racial, resvalou para a discussão sobre a mestiçagem, tema bastante caro àqueles que desejam diluir as tensões existentes nas relações étnico-raciais no Brasil. Esse fato, especificamente relacionado à população do Nordeste, aparece tematizado na obra do intelectual negro Guerreiro Ramos (1995), atento desde 1957 a esta dificuldade da região e do Brasil no tocante à identidade étnico-racial. Para ele, esta patologia social:

[...] consiste em que, no Brasil, principalmente naquelas regiões [Norte e Nordeste] as pessoas de pigmentação mais clara tendem a manifestar, em sua autoavaliação estética, um protesto contra si próprias, contra a sua condição étnica objetiva (RAMOS, 1995, p. 222).

O autor continua analisando os resultados do censo de 1940 e pontua que, "no Brasil, o negro é mais negro nas regiões onde os brancos são maioria e é mais claro nas regiões onde os brancos são minoria" (RAMOS, 1995, p. 225). Não podemos deixar de considerar que o texto de Ramos foi escrito há cinquenta anos, mas nos dia de hoje ainda é pertinente avaliarmos suas palavras, principalmente considerando os resultados das nossas análises nesta pesquisa. É verdade 
que não conhecemos estudos que avaliem precisamente a questão abordada por Ramos, porém as investigações sobre o Nordeste têm apontado maior índice de desigualdades, piores condições de vida e maior nível de conservadorismo.

Na cidade de Horizonte/CE, segundo depoimento do professor responsável pela disciplina, para o desfile de Sete de Setembro, escolheram uma estudante de "pele preta" para representar a "miss negra". O professor relatou o fato como prova de que o desfile da independência visava incorporar todas as etnias componentes da comunidade imaginada Brasil, mas explica de imediato que a escolha deveu-se à "atuante participação da aluna nas atividades da escola e não pela sua estética", como se houvesse no Brasil ou em outro qualquer lugar apenas um modelo de beleza. Por outro lado, não percebe que, ao escolher uma rainha de "pele clara" e uma miss de "pele preta", ele e/ou a escola continuam reiterando os padrões de representação hierarquicamente marcados e que reforçam as "justificativas" para a produção e reprodução de comportamentos racistas, como já foi referido nas Diretrizes Curriculares Nacionais para Educação das Relações Étnico-Raciais.

A lógica predominante nas entrevistas e nas conversas informais parece fundamentar-se nos discursos da cordialidade e tolerância ao outro; racismo e a discriminação são temas imediatamente rechaçados, sem qualquer reflexão crítica. "Isto não acontece aqui" parece um bordão repetido pela maioria de gestores/as e professores/as, os quais mascaram para si e para os outros as práticas racistas ainda vigentes na sociedade resguardadas sob o véu do discurso da democracia racial e que, com certeza, de modo mais pontual ou não, aparecem nas conversas e nas respostas às entrevistas.

No tocante às ações afirmativas, um dos gestores, mesmo não tendo sido questionado sobre o assunto, fez questão de posicionar-se contrário às cotas, posto que, segundo ele, o "Brasil é todo misturado" e, consequentemente, não se sabe quem é branco ou negro - fala que não traz originalidade alguma, pois reitera a dificuldade de os brasileiros e brasileiras encararem o racismo como estruturante da nossa sociedade. $\mathrm{O}$ empenho em evidenciar a necessidade de corrigir as desigualdades foi mais enfatizado apenas nas duas escolas de Salvador pesquisadas. Os gestores das mesmas mostraram-se dedicados e atentos no combate às atitudes discriminatórias no contexto escolar e empenhados em fazer da escola um espaço da diversidade étnica e cultural, estimulando os projetos dos docentes e tentando, com limites, é verdade, demonstrar a importância do trabalho dos afrodescendentes para construção da riqueza do país.

Entretanto, o discurso público dos/as outros/as gestores/as e professores/ as sugere que os projetos e/ou disciplinas vistos como práticas pedagógicas de implementação da Lei visam corrigir comportamentos e atitudes de discriminação étnico-racial que "por acaso" ocorram nas escolas. Ora, é por demais sabido 
que as diferenças, inclusive as fenotípicas, têm sido utilizadas para discriminar e excluir estudantes no universo escolar. É interessante registrar que enquanto alguns gestores não percebem as situações discriminatórias, os/as estudantes e os/as professores/as envolvidos/as nos projetos percebem e relatam situações de discriminação e comportamentos racistas advindos de professores, funcionários e estudantes das escolas.

\section{Formação e material didático}

As publicações produzidas e distribuídas pelo MEC com o objetivo de auxiliar os docentes na abordagem das temáticas inerentes à Lei não chegam a todas as escolas; e, quando chegam, ou ficam guardadas de modo desorganizado em estantes e quase inacessíveis a professores e a alunos ou não são sequer desencaixotadas. A maioria dos/as professores/as desconhecia a existência dos citados livros, outros sabiam que chegaram DVDs e livros, mas estes não tinham sido disponibilizados para o uso e uma das escolas nem possui biblioteca (Escola 3).

Os NEABs, no corpus de nossa pesquisa, na maior parte dos casos não se constituem como referência na formação e nem no acompanhamento das práticas pedagógicas voltadas para a implementação da Lei. Tínhamos a expectativa de que os núcleos das universidades estivessem acompanhando mais de perto as atividades dos professores e das escolas.

Quanto à formação, no conjunto das escolas visitadas, apenas alguns professores de Salvador, de Jequié e de Horizonte participaram de atividades de formação com conteúdos especificamente voltados para a Lei 10.639/2003. Em Salvador, a Secretaria Municipal de Educação há algum tempo vem desenvolvendo ações para inclusão da diversidade étnico-racial e cultural. Várias formações de professoras foram coordenadas pelo Programa de Educação para Igualdade Racial e de Gênero do Centro de Estudos Afro-Orientais/UFBA CEAO, representantes de blocos afros e de outros movimentos sociais com o objetivo de tratar da diversidade, de propor uma escola plural, com educadores formados na temática de raça e gênero, entre outros temas. A Prefeitura editou e distribuiu livros, antologias e textos vários para que as professoras pudessem ter em mãos materiais que estimulassem uma reflexão sobre a sua própria formação e que pudessem contribuir para a utilização de metodologias mais adequadas à inclusão da história e cultura afro-brasileira nas escolas de Salvador. Depoimentos da equipe de trabalho do CEAFRO indicam que participaram do Programa cerca de 300 professoras e professores das escolas municipais de Salvador. 
Vale ressaltar, entretanto, que a formação em Jequié é resultado do esforço e interesse pontual de quatro professoras, sem, segundo elas, qualquer apoio da Secretaria Municipal de Educação; em Horizonte, a formação restringiu-se a um professor, que deveria ter a função de multiplicador a um pequeno grupo de professores que terminaram sendo responsáveis por uma disciplina: História e Cultura Afro-Brasileira. Entretanto, de acordo com o que observamos, não houve o acompanhamento da formação - fato que gerou a repetição de estereótipos negativos a respeito das culturas afro-brasileiras pelo professor na aula que observamos.

Pareceu-nos, como já ressaltamos, que a criação da disciplina funciona como uma espécie de "modo mais fácil" de demonstrar que a secretaria municipal, e por extensão a escola, está implementando a Lei, já que os/as professores/as de outras disciplinas não trocam informações nem interagem com os conteúdos ministrados pela disciplina específica - fato que, em nosso entender, inviabiliza o cumprimento das Diretrizes e consecução dos objetivos da Lei. Entendemos que o professor formado em um sistema social e educacional eurocêntrico e racista deveria ter a oportunidade de ser capacitado para lidar com seus preconceitos a fim de, posteriormente, contribuir para que haja alterações significativas nas suas práticas.

Abordando a proposta de formação de professoras em Salvador, Nazaré Lima (2005, p. 20) aponta que:

O trabalho implica, portanto, que se vejam criticamente como professoras, instigadas a refazerem sua prática de forma que incorpore a identidade racial e de gênero, a procedência, jeito de ser etc. dos/as alunos/as enquanto elementos importantes para conseguir sua vinculação ao conhecimento formal oferecido pela escola.

A formação deve ser, pois, continuada para que viabilize novas práticas educativas a partir das realidades dos/as professores/as e das necessidades básicas da educação dos alunos em confluências com suas trajetórias de vida.

Em uma das escolas, que embora possua um projeto premiado na área, muitos/as professores/as e coordenadores/as não parecem se esforçar para obterem informações sobre as temáticas da Educação das Relações Étnico-Raciais; não fazem sequer referências a pesquisas em bibliotecas ou sites, embora algumas das escolas possuam salas de informática. Outro dado a registrar é que, embora quase todas as escolas possuam computadores, pareceu-nos que para a maioria dos/as professores/as estas ferramentas não se constituíram efetivos instrumentos de pesquisa. 


\section{Avanços e limites do trabalho}

A Lei 10.639/2003 não é desconhecida dos gestores, o que pode significar que ela foi divulgada nos meios de comunicação e nos materiais enviados às escolas pelo MEC. No entanto, constatamos que é fraco o seu grau de institucionalização. Porém, algumas escolas não fazem referência à Lei 10.639/2003 no PPP; gestores/as e professores/as não dominam os conteúdos e nem os métodos de ensino que contemplem História e Cultura Afro-Brasileira e Africana e a Educação das Relações Étnico-Raciais; os gestores não demonstraram familiaridade com as propostas das Diretrizes Curriculares Nacionais para Educação das Relações Étnico-Raciais e alguns a desconhecem totalmente.

Pelo exposto, consideramos que, ainda nos dias atuais, urge ser feito um trabalho intensivo com secretários de educação e gestores, para que não somente entendam a obrigatoriedade, mas principalmente a importância de as escolas seguirem as citadas Diretrizes, para que consigamos contribuir para a formação de um Brasil mais equânime.

As escolas de Jequié, Horizonte, São Luís e Aracaju não possuem em sua estrutura uma atmosfera de trabalho que favoreça discussões sobre o tema da Educação das Relações Étnico-Raciais e a proposição criativa de outras práticas pedagógicas inovadoras. Professores desmotivados, carência de material didático, silenciamento e apagamento das situações de racismos e discriminação presentes na escola não contribuem para a compreensão da diversidade étnico-racial brasileira e para a necessidade de a diferença e sua riqueza serem incorporadas aos conteúdos e práticas da escola.

De modo geral, no tocante à interpretação da Lei e dos objetivos das políticas de reparação, reconhecimento e valorização da história e cultura afrodescendentes no Brasil, não foram atribuídos sentidos que viabilizassem a materialização de práticas pedagógicas consistentes. Isto é, as prefeituras, em alguns casos, devido à obrigatoriedade ou por compreensão da necessidade, propõem e implementam políticas mais gerais que não propiciam o alcance dos objetivos ou diluem a sua eficácia de tal modo que se torna difícil afirmar que as práticas refletem ou ecoam propósitos políticos de reparação ou de afirmação das identidades colocadas à margem do discurso nacional.

Por meio das entrevistas dos/as professores/as, mesmo que em algumas escolas pesquisadas não se desenvolvam práticas pedagógicas que atendam às expectativas da Lei e das Diretrizes, percebemos que houve certa mudança no modo como as pessoas negras passaram a lidar com sua identidade étnico-racial após a implementação da Lei 10.639/2003. Com a possibilidade do trabalho de 
valorização da autoestima e o maior conhecimento a respeito da história do negro no Brasil, professores/as e gestores/as, de uma forma ou de outra, acabaram por coibir explicitações de comportamentos e atitudes discriminatórios.

No entanto, contraditoriamente, tanto em São Luís como em Horizonte, mesmo considerando que são cidades com grande número de afrodescendentes, houve tentativa de alunos e de funcionários de ridicularizarem até mesmo as pesquisadoras, através de zombaria quanto às roupas (estampadas e modelos "afro") e aos penteados dos cabelos das mesmas. Os sistemas de representação hegemônicos ignoram todo o caráter individual do conceito de estética e impuseram que alguns traços do fenótipo branco são os traços considerados belos, ao passo que os fenótipos dos demais grupos étnico-raciais, à medida que mais se afastam do "modelo homogeneizador", são considerados "feios" e ridículos, "impuros". Este discurso tenta criar uma norma que hierarquiza as identidades e diferenças. Normalizar significa, segundo Tomaz Tadeu da Silva (2003, p. 83), atribuir a uma "identidade todas as características positivas possíveis, em relação às quais as outras identidades só podem ser avaliadas de forma negativa".

As Diretrizes Curriculares Nacionais para Educação das Relações Étnico-Raciais são pouco citadas durante as conversas, não nos parecendo que gestores/ as e professores/as tenham se debruçado ou mesmo lido atentamente as mesmas. O Plano Nacional de Implementação da Lei 10.639/2003 é vagamente conhecido. Diante deste quadro, sugerimos que as Secretarias de Educação organizem encontros regionais com gestores e professores para leitura, discussão e análise dos textos da Lei e das Diretrizes. Se a Lei hoje parece ser "conhecida" por todos os gestores devido ao trabalho de divulgação realizado pelo MEC e pelas secretarias, para que a obrigatoriedade da Lei de fato atinja aos seus objetivos é necessário que as Diretrizes e o Plano Nacional também sejam divulgados e incorporados aos planos e às atividades das escolas.

\section{REFERÊNCIAS}

ALBUQUERQUE JÚNIOR, Durval M. de. A invenção do Nordeste e outras artes. São Paulo: Cortez, 2006.

BRASIL. Presidência da República. Lei 10.639 de 9 de janeiro de 2003. Altera a Lei 9.394, de 20 de dezembro de 1996, que estabelece as diretrizes e bases da educação nacional, para incluir no currículo oficial da Rede de Ensino a obrigatoriedade da temática "História e Cultura Afro-Brasileira", e dá outras providências. Disponível em: $<$ http:// www.planalto.gov.br/ccivil_03/leis/2003/L10.639.htm>. Acesso em: 23/06/2012. 
. Ministério da Educação/Secretaria de Educação Continuada, Alfabetização e Diversidade. Diretrizes Curriculares Nacionais para a Educação das Relações Étnico-Raciais e para o Ensino de História e Cultura Afro-Brasileira e Africana. Brasilia, 2004. . Plano Nacional das Diretrizes Curriculares Nacionais para a Educação das Relações Étnico-Raciais e para o Ensino de História e Cultura Afro-Brasileira e Africana. Brasília: SECAD; SEPPIR, 2009.

HALL, Stuart. Da diáspora. Belo Horizonte: UFMG; Brasília: Representação UNESCO, 2003.

LIMA, Maria Nazaré Mota de (Org.). Escola Plural, a diversidade está na sala: formação de professoras em História e Cultura Afro-Brasileira e Africana. São Paulo: Cortez; Brasília: UNICEF; Salvador: CEAFRO, 2005.

RAMOS, Guerreiro. Introdução crítica à sociologia brasileira. Rio de Janeiro: UFRJ, 1995.

SILVA, Tomaz Tadeu. Identidade e diferença. Petrópolis: Vozes, 2003.

Texto recebido em 12 de junho de 2012.

Texto aprovado em 29 de julho de 2012. 